\title{
Pembuatan Bioetanol dari Pati Umbi Uwi (Discorea alata) melalui Proses Fermentasi dan Distilasi
}

\author{
Hargono* \\ Departemen Teknik Kimia, Fakultas Teknik Universitas Diponegoro \\ Jl. Prof. H. Soedarto, SH., Tembalang, Semarang, 50275, Indonesia \\ Email: hargono@che.undip.ac.id
}

\begin{abstract}
Abstrak
Bioetanol adalah nama lain etanol yang dapat dibuat dari bahan baku biomasa. Tanaman Uwi (Discorea alata) mudah tumbuh di lereng-lereng gunung, hutan sebagai tanaman liar, namun tanaman ini ada yang sengaja ditanam orang. Tanaman Uwi mengandung karbohidrat cukup tinggi (32,64\%) sehingga dapat dimanfaatkan sebagai bahan baku pembuatan bioetanol. Pada penelitian ini umbi Uwi terlebih dulu dibuat pati agar memudahkan terjadinya proses hidrolisis dan fermentasi. Proses pembuatan pati Uwi adalah dengan mengekstrak bubur (hasil parutan) Uwi menggunakan air. Proses hidrolisis dan fermentasi dilakukan secara serentak atau Simultaneous Saccharification and Fermentation (SSF). Konsentrasi pati Uwi $200 \mathrm{~g} / \mathrm{L}$, konsentrasi enzim (Stargen ${ }^{\mathrm{TM}}$ 002) 1,5\% (w/W), konsentrasi yeast 1,10\% (w/w) dan pada suhu $30^{\circ} \mathrm{C}$. Hasil proses SSF adalah konsentrasi bioetanol kadar rendah, sehingga agar kemurnian bioetanol meningkat perlu dilakukan distilasi. Proses distilasi menggunakan distilasi 2 tahap, terdiri dari 2 kolom, meliputi kolom 1 tanpa bahan isian dilengkapi pipa pendingin yang berbentuk spiral, sedangkan kolom 2 berisi bahan isian yaitu packing. Proses distilasi 2 tahap masing-masing ini dioperasikan pada suhu $78^{\circ} \mathrm{C}$. Tujuan penelitian ini adalah mempelajari pengaruh waktu SSF terhadap konsentrasi bioetanol dan mempelajari waktu distilasi tahap 1 dan 2 terhadap konsentrasi bioetanol. Proses SSF dilakukan selama 90 jam. Hasil terbaik proses SSF dicapai selama 72 jam yang menghasilkan konsentrasi bioetanol 12,30\%. Proses distilasi 1 dan 2 dilakukan masing-masing selama 105 menit. Hasil terbaik dari distilasi tahap 1 dan tahap 2dicapai selama waktu masing-masing 90 menit, yaitu konsentrasi bioetanol 27,93\% dan 85,30\%. Perancangan alat distilasi 2 tahap ini layak digunakan sebagai alat pemunian bioetanol hasil SSF.
\end{abstract}

Kata kunci : Pati Uwi, SSF, distilasi dua tahap, bioetanol

\section{Abstract \\ Making Bioethanol from Uwi Tuber Starch (Discorea alata) through Fermentation and Distillation Processes}

Bioethanol is another name for ethanol which can be made from biomass feedstock. The Uwi (Discorea alata) plant contains quite high carbohydrate $(32,64 \%)$ so that it can be used as raw material for bioethanol production. The Uwi tubers were made starch in order to facilitate the hydrolysis and fermentation processes. The process of to produce Uwi starch is to extract the pulp (grated) Uwi using water. The hydrolysis and fermentation processes are carried out simultaneously or Simultaneous Saccharification and Fermentation (SSF). Uwi starch concentration $200 \mathrm{~g} / \mathrm{L}$, enzyme concentration $(1.5 \%(\mathrm{~W} / \mathrm{W})$, yeast concentration $1.10 \%(\mathrm{~W} / \mathrm{W})$ and at a temperature of $30^{\circ} \mathrm{C}$. The result of the SSF process is a low concentration of bioethanol, so that in order to increase the purity of bioethanol, using distillation. The distillation process uses 2-stage distillation, consisting of 2 columns, including the first without filling, equipped with a spiral cooling pipe, while the second column contains stuffing. The 2-stage distillation process each is operated at $78^{\circ} \mathrm{C}$. The objective of this study was to 
study the effect of SSF time on bioethanol concentration and to study the distillation time of stages 1 and 2 on the concentration of bioethanol. The best result of SSF process was achieved for 72 hours which resulted in a bioethanol concentration of $12.30 \%$. The best results from the distillation stage 1 and stage 2 were achieved during each time of 90 minutes, namely the bioethanol concentration of $27.93 \%$ and $85.30 \%$. The design of this 2-stage distillation apparatus is suitable for use as a means of abolishing the bioethanol produced by SSF.

Keywords : Uwi starch, SSF, two stage distillation, bioethanol.

\section{PENDAHULUAN}

Tanaman Uwi (Discorea alata) banyak tumbuh di Indonesia, terutama di lereng-lereng gunung, hutan sebagai tanaman liar. Tanaman ini menghasilkan umbi. Rakyat Indonesia jarang sekali mengkonsumsi umbi ini karena cara pengolahan umbi ini harus berhati-hati dan pencuciannya membutuhkan waktu yang lama. Pemanfaatan umbi ini dapat digunakan sebagai makanan alternatif terutamama bagi orang yang sedang melalakukan diet karena kandungan karbohidratnya tidak tinggi. Umbi tanaman ini dapat dikonversi juga menjadi bahan bakar alternatif, sebagai contoh bioetanol. Bioetanol merupakan salah satu bahan bakar alternatif pengganti bahan bakar fosil yang dapat diperbaruhi dan lebih ramah lingkungan (Farrell et al., 2006) dan (Karagoz et al., 2012). Bioetanol mudah dibuat dari bermacam-macam bahan baku yang berasal dari produk pertanian (Jørgensen et al., 2007), berbasis pati: singkong, umbi gadung, jagung, gandum, sagu (Favaro et al., 2015) berbasis lignoselullose: jerami padi, eceng gondok (water hyacinth), sugarcane bagasse, corn stalk, grass, pineapple peel (Shaheen et al., 2013), berbasis gula: gula tebu (Saccharum officinarum), gula bet (Beta vulgaris), molasses (Ensinas et al., 2009)

Proses fermentasi dengan metode Simultaneous Saccharification and Fermentation (SSF) dari berbagai macam feedstock umumnya menghasilkan etanol kadar rendah. Penelitian SSF menggunakan yeast $S$. carlsbergensis menghasilkan etanol maksimum 15,9 g/L (2,21\%) setelah 48 jam (Scordia et al., 2010). Selanjutnya penelitiannya menggunakan design eksperimental untuk mengoptimalkan etanol melalui SSF dengan menggunakan selulase dan yeast $S$. stipitis menghasilkan etanol $18 \mathrm{~g} / \mathrm{L}(2,5 \%)$ (Scordia et al., 2010). Penelitian SSF terhadap giant reed, menghasilkan konsentrasi etanol $39 \mathrm{~g} / \mathrm{L}(5,41 \%)$ selama 72 jam (Silva et al., 2015)

Proses pemisahan atau pemurnian digunakan untuk memurnikan crude etanol hasil fermentasi (Utama et al., 2016). Pemurnian etanol hasil fermentasi dapat dilakukan menggunakan distilasi (Lei and Chen, 2003), adsorpsi (Fujita et al., 2011) dan membran pervaporasi (Wei et al., 2009). Penelitian ini bertujuan untuk mempelajari pengaruh waktu fermentasi (SSF) terhadap konsentrasi etanol pada konsentrasi pati umbi Uwi (Discorea alata) $200 \mathrm{~g} / \mathrm{L}$ pada suhu $30^{\circ} \mathrm{C}$ dan mempelajari pengaruh waktu distilasi 2 tahap terhadap konsentrasi etanol.

\section{METODOLOGI}

Umbi Uwi (Discorea alata) berumur 10 bulan didapat dari desa Sukorejo, Kecamatan Gunung Pati, Semarang, Jawa Tengah-Indonesia, selanjutnya umbi ini dibuat pati yang merupakan bahan baku pembuatan bioetanol. Kandungan pati 32,64\%Pembuatan pati Uwi yaitu sebanyak 5 $\mathrm{kg}$ umbi Uwi yang dipeoleh dari petani dicuci terlebih dahulu menggunakan air agar bersih dan terpisah kotoran (tanah). Selanjutnya umbi ini dikuliti menggunakan pisau agar umbi terpisah dari kulitnya. Setelah diperoleh umbi maka umbi ini dicuci berkali-kali (biasanya 3 kali) menggunakan air yang mengalir sampai bersih. Untuk memperoleh pati yang maksimal umbi yang telah bersih ini diparut menggunakan alat parut tradisional sehingga umbi ini akan berubah bentuk menjadi bubur umbi Uwi. Bubur umbi ini selanjutnya diekstrak menggunakan air dengan cara diremas-remas agar diperoleh pati. Kondisi terakhir kalinya adalah campuran antara pati dan air. Selanjutnya campuran bahan ini dilakukan proses pemisahan menggunakan centrifuge pada kecepatan $100 \mathrm{rpm}$ selama 20 menit. Pati umbi Uwi akan terpisah dari airnya, selanjutnya 
dikeringkan mengunakan tray dryer pada suhu $60^{\circ} \mathrm{C}$ selama $15 \mathrm{jam}$ (Hargono et al., 2017)

Potassium sodium tartrate tetrahydrate dan 3,5-Dinitrosalicylic acid (Merck), NaOH (98\%, glukosa (99.5\%, Merck) dan etanol (99.5\%, Merck), $\left(\mathrm{NH}_{4}\right)_{2} \mathrm{HPO}_{4}, \mathrm{MgSO}_{4} .7 \mathrm{H}_{2} \mathrm{O}$ dan yeast extract semuanya dibeli dari Sigma-Aldrich Indonesia. Enzim jenis GSHE sebagai Stargen ${ }^{\mathrm{TM}} 002$ diperoleh dari Genencor International (USA) (Genencor, 2009) Enzim ini berisi Aspergillus kawachii $\alpha$ amylase revealed di dalam $T$. reesei and glucoamylase dari $T$. reesei. Enzim $\alpha$-amilase dan glukoamilase yang bekerja secara sinergi untuk menghidrolisis granula pati menjadi glukose. Aktivitas enzim 570 GAU/g dan pH 4-4,5. Mikroorganisme yang digunakan adalah Saccharomyces cereviceae yaitu Baker's yeast, produksi PT. Pakmaya didapat dari Toko Kabita, Semarang. Sebelum digunakan disimpan dalam almari pendingin. Saccharomyces cereviceae discatter dalam aquades pada suhu kamar pada konsentrasi $10 \mathrm{~g} / \mathrm{L}$.

Tahapan pra hidrolisis terlebih dulu dilakukan dengan tujuan yaitu memenuhi tahapan SSF. Hidrolisis pati Uwi dilakukan dalam erlenmeyer $250 \mathrm{~mL}$. Konsentrasi pati umbi Uwi $200 \mathrm{~g} / \mathrm{L}$, konsentrasi enzim 1,5\% (w/w), pH 4,5. Campuran di dalam erlenmeyer dipanaskan dalam water bath sampai suhu $50^{\circ} \mathrm{C}$ selama 30 jam pada kecepatan $100 \mathrm{rpm}$. Selanjutnya slurry didinginkan sampai suhu $30^{\circ} \mathrm{C}$ dan dilakukan inkubasi selama 18 jam. Selanjutnya slurry dipisahkan antara cake dan filtratnya menggunakan centrifuge. Filtrat yang ada dianalisis untuk menentukan jumlah glukosa yang dibebaskan. Fermentasi hidrolisis enzimatik dilakukan dengan menggunakan konsep SSF. Pra hidrolisis dilakukan untuk meningkatkan glukosa pada awal fermentasi sehingga hasil glukosa tersedia dan dapat difermentasi oleh yeast Saccharomyces cereviceae menjadi etanol konsentrasi rendah. Proses SSF ini dilakukan terhadap pati umbi Uwi pada konsentrasi $200 \mathrm{~g} / \mathrm{L}$ dalam reaktor pada volume $1 \mathrm{~L}$. Konsentrasi enzim 1,5\% (w/w). Peralatan ini dilengkapi dengan kontrol $\mathrm{pH}$. pH medium fermentasi dipertahankan 4,5 selama "cultivation" dikontrol secara hati-hati menggunakan $3 \mathrm{M} \mathrm{NaOH}$. Selanjutnya pada media fermentasi ditambahkan beberapa nutrien:
$(\mathrm{NH} 4)_{2} \mathrm{HPO}_{4} 0.5 \mathrm{~g} \mathrm{~L}^{-1}, \mathrm{MgSO}_{4} .7 \mathrm{H}_{2} \mathrm{O} 0.025 \mathrm{gL}^{-1}$ dan yeast extract $1.0 \mathrm{gL}^{-1}$ selama $15 \mathrm{jam}$ dalam shakerinkubator pada suhu $37^{\circ} \mathrm{C}$ dan $80 \mathrm{rpm}$. Selanjutnya pada medium fermentasi ini ditambahkan yeast kering $5 \mathrm{~g} / \mathrm{L}$ dan dilakukan percobaan selama $90 \mathrm{jam}$. Sampel diambil secara periodik : 6, 12, 18 sampai 90 jam selanjutnya sampel ini dianalisis kandungan etanol dan glukosa menggunakan high performance liquid chromatography (HPLC) Aminex HPX-87H column. Hasil proses fermentasi adalah berupa ethanol broth yang mempunyai kandungan etanol yang rendah. Untuk meningkatkan kadar etanol dilakukan menggunakan distilasi 2 tahap seperti ditunjukkan pada Gambar 1. Tahap satu ethanol broth dipanaskan dalam boiler T-01 pada suhu $78^{\circ} \mathrm{C}$ sehingga terbentuk uap campuran etanol-air. Campuran uap etanol-air yang berada di dalam pipa spiral (dalam Kondensor A) dikondensasi selama 15-120 menit menggunakan pendingin air. Setiap interval waktu 15 menit sampel hasil kondensasi dianalisis konsentrasi etanol menggunakan HPLC. Hasil etanol terbaik dari tahap1 digunakan sebagai umpan distilasi 2, dengan memanaskan sistem dalam boiler T-02 tersebut sampai suhu $78^{\circ} \mathrm{C}$. Pemurnian tahap 2 dilakukan di dalam kolom kondensor (B) yang berisi bahan isian berupa packing selama periode waktu 6,12,18 sampai 78 jam. Hasil etanol keluaran dari kolom kondensor B merupakan hasil utama dari serangkaian proses distilasi tahap 2, selanjutnya konsentrasi etanol dianalisis menggunakan HPLC.

\section{HASIL DAN PEMBAHASAN}

Hasil SSF konsentrasi glukosa dan etanol pada konsentrasi pati Uwi $200 \mathrm{~g} / \mathrm{L}$, pada $30^{\circ} \mathrm{C}$ dan $\mathrm{pH} \quad$ 4,5 dari periode waktu 6 sampai 78 jam ditunjukkan pada Tabel 1. Selama SSF dari 6 sampai 12 jam, konsentrasi glukosa yang menjadi $56,78 \mathrm{~g} / \mathrm{L}$, selanjutnya selama waktu 18 sampai 90 jam konsentrasi glukosa cenderung turun sampai 78 jam yaitu dari 48,90 g/L sampai 5,09 g/L, setelah 78 jam konsentrasi glukosa cenderung tetap pada 5,09 g/L. Kenaikan konsentrasi selama 6-12 jam disebabkan karena pada proses SSF ini memasuki tahap pre-hidrolisis (Silva et al., 2015) yaitu aktivitas enzim selama hidrolisis pati Uwi yang menghasilkan konsentrasi glukosa mencapai 
maksimum. Hal ini sebagai akibat proses SSF yang harus menyediakan glukosa untuk diubah menjadi etanol. Berbeda dengan glukosa, selama SSF konsentrasi etanol cenderung naik seperti ditunjukkan pada Tabel 1. Selama SSF dari waktu 6 sampai 72 jam, konsentrasi etanol naik dari 40,18
g/L sampai $88,65 \mathrm{~g} / \mathrm{L}$. Selanjutnya selama waktu proses melebihi 78 jam konsentrasi etanol cenderung tetap yaitu $88,60 \mathrm{~g} / \mathrm{L}$. Hal ini terjadi karena ketersediaan glukosa dalam jumlah yang cukup untuk diproses secara fermentasi oleh yeast Saccharomyces cerrevisiae menjadi etanol.

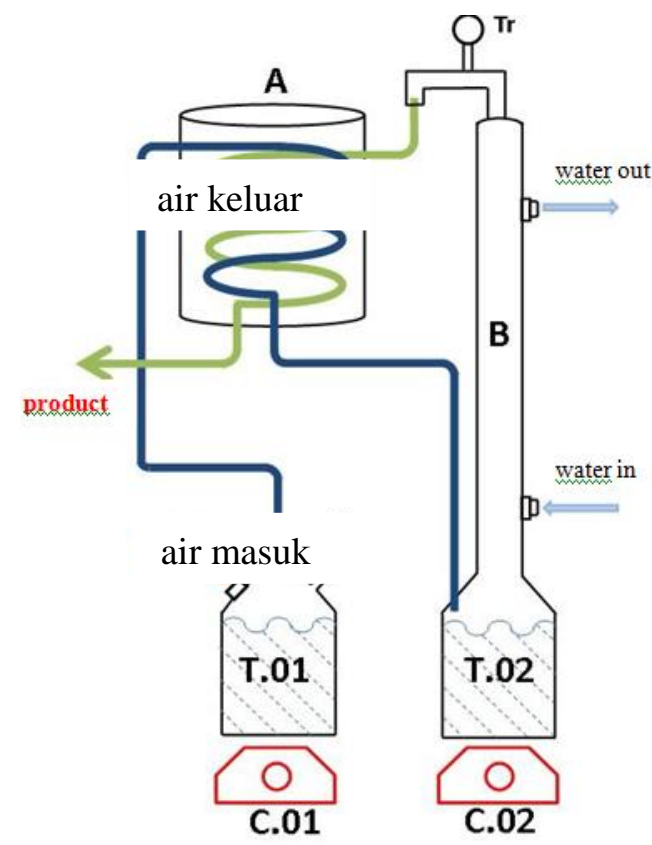

Gambar 1. A. Kondensor dengan pendingin air, B. Kolom distilasi berisi packing, C.01 pemanas -1 untuk Boiler-1, C.02 pemanas-2 untuk Boiler-2, T-01 Boiler-1, T-02 Boiler-2, dan Tr Termometer.

Tabel 1. Pengaruh waktu fermentasi (SSF) terhadap konsentrasi glukosa dan konsentrasi etanol pada Konsentrasi pati Uwi $200 \mathrm{~g} / \mathrm{L}, 30^{\circ} \mathrm{C}$ dan $\mathrm{pH} 4$

\begin{tabular}{cccc}
\hline Waktu, jam & $C_{\text {glukosa }} \mathrm{g} / \mathrm{L}$ & $\mathrm{C}_{\text {etanol, }} \mathrm{g} / \mathrm{L}$ & $\mathrm{C}_{\text {etanol, }}(\%)$ \\
\hline 0 & 0 & 0 & 0 \\
6 & 32,24 & 40,18 & 5,58 \\
12 & 56,78 & 49,29 & 6,84 \\
18 & 48,90 & 57,84 & 8,03 \\
24 & 18,59 & 65,82 & 9,14 \\
30 & 13,02 & 71,62 & 9,94 \\
36 & 12,51 & 73,75 & 10,24 \\
42 & 11,29 & 75,46 & 10,48 \\
48 & 8,94 & 77,86 & 10,81 \\
54 & 8,48 & 82,25 & 11,42 \\
60 & 5,46 & 84,12 & 11,68 \\
66 & 5,23 & 86,54 & 12,01 \\
72 & 5,11 & 88,65 & 12,30 \\
78 & 5,09 & 88,62 & 12,31 \\
84 & 5,09 & 88,60 & 12,30 \\
90 & 5,09 & 88,60 & 12,30 \\
\hline
\end{tabular}


Penambahan ragi pada proses fermentasi SSF selama 12 jam menghasilkan konsentrasi glukosa $28 \mathrm{~g} / \mathrm{L}$ (Silva et al. 2015). Hasil glukosa ini digunakan untuk fermentasi SSF selama 78 jam menghasilkan konsentrasi etanol $39 \mathrm{~g} / \mathrm{L}$. Hargono et al., (2015) melakukan penelitian SSF pati singkong pada konsentrasi $200 \mathrm{~g} / \mathrm{L}$, menggunakan Stargen TM $002 \quad(0,1 \% \quad \mathrm{w} / \mathrm{w})$ dan yeast Saccharomyces cerrevisiae menghasilkan konsentrasi etanol 36,16 g/L. Kusmiyati, et al., (2016) melakukan studi hidrolisis tepung Iles-iles (Amorphophalus campanulatus) pada konsentrasi $10 \%$ untuk memproduksi gula reduksi yang akan digunakan sebagai bahan baku fermentasi menggunakan Zymomonas mobilis. Kondisi optimum dicapai pada $\mathrm{pH} 4.5,30^{\circ} \mathrm{C}$ selama 120 jam, menghasilkan etanol $10.33 \%(\mathrm{v} / \mathrm{v})$.

\section{Pengaruh Waktu Distilasi terhadap Konsentrasi Etanol}

Proses pemurnian etanol melalui distilasi tahap-1 dilakukan terhadap ethanol broth hasil fermentasi SSF terbaik yaitu $88,65 \mathrm{~g} / \mathrm{L}$ atau 12,30\% (waktu 72 jam). Selanjutnya setelah dilakukan pemurnian menggunakan distilasi tahap-1 hasil etanol yang didapat seperti ditunjukkan pada Tabel 2. Selama waktu distilasi 15-105 menit terjadi kenaikan konsentrasi etanol dari $11,06 \%$ sampai $27,92 \%$, selanjutnya setelah proses distilasi dilanjutkan sampai waktu 105 menit konsentrasi etanol hampir tetap, yaitu 27,93\%. Proses distilasi tahap 1 terjadi kondensasi di dalam kolom A tanpa menggunakan bahan isian sehingga kenaikan konsentrasi etanol hanya sampai $27,93 \%$. Hal ini diasumsikan bahwa proses distilasi ini hanya terdiri 1 stage sehingga konsentrasi etanol hanya terbatas pada $27,93 \%$, walaupun waktu distilasi dinaikkan sampai 105 jam, hasil konsentrasi etanol cenderung tetap, seperti ditunjukkan pada Tabel 2.

Distilasi tahap 2 merupakan cara yang digunakan untuk meningkatkan konsentrasi etanol dari hasil distilasi tahap $1(27,93 \%)$. Selama waktu 90 menit distilasi ini menghasilkan konsentrasi etanol 85,30\% seperti ditunjukkan pada Tabel 3.
Tabel 2. Pengaruh Waktu Distilasi Tahap 1 terhadap Konsentrasi Etanol

\begin{tabular}{cc}
\hline $\begin{array}{c}\text { Waktu } \\
\text { (menit) }\end{array}$ & $\begin{array}{c}\text { Konsentrasi etanol } \\
(\mathrm{g} / \mathrm{L} \%)\end{array}$ \\
\hline 0 & 11,06 \\
15 & 12,94 \\
30 & 16,06 \\
45 & 18,27 \\
60 & 19,55 \\
75 & 24,16 \\
90 & 27,92 \\
105 & 27,93 \\
\hline
\end{tabular}

Tabel 3. Pengaruh Waktu Distilasi Tahap 2 terhadap Konsentrasir Etanol

\begin{tabular}{cc}
\hline Waktu (menit) & Konsentrasi etanol (\%) \\
\hline 0 & 30,72 \\
60 & 74,68 \\
75 & 83,25 \\
90 & 85,30 \\
105 & 81,64 \\
120 & 81,63 \\
\hline
\end{tabular}

Distilasi ini merupakan metode untuk memisahkan campuran biner etanol-air. Menurut Huang et al., (2008) metode distilasi pemisahan campuran biner etanol-air hanya dapat menghasilkan konsentrasi etanol maksimum $95,63 \%(\mathrm{w} / \mathrm{w})$ karena terbatas pada titik azeotrop. Vane et al., (2012) melakukan studi pemisahan etanol hasil fermentasi ethanol broth pada konsentrasi $5 \%$ pada flowrate 145 $\mathrm{g} /$ menit menggunakan distilasi terintegrasi dengan membran dihasilkan konsentrasi etanol 63,5 sampai $98,5 \%$

\section{KESIMPULAN}

Proses SSF terhadap pati umbi Uwi pada konsentrasi $200 \mathrm{~g} / \mathrm{L}$ selama 72 jam menghasilkan glukosa $5,11 \mathrm{~g} / \mathrm{L}$, sedangkan konsentrasi ethanol broth $12,30 \%$. Pada tahap pemurnian terhadap ethanol broth menggunakan distilasi tahap 1 dan tahap 2 diperoleh masing-masing konsentrasi etanol $27,92 \%$ dan $85,30 \%$ selama 90 menit Rancangan peralatan distilasi 2 tahap ini layak digunakan untuk pemurnian hasi fermentasi. 


\section{DAFTAR PUSTAKA}

Ensinas, A.V., Modesto, M., Nebra, S.A. \& Serra, L., 2009. Reduction of irreversibility generation in sugar and ethanol production from sugarcane. Energy, 34(5):680-688.

Farrell, A.E., Plevin, R.J., Turner, B.T., Jones A.D., O'Hare, M., \& Kammen ,D.M., 2006. Ethanol can contribute to energy and environmental goals. Science. 311:506-508.

Favaro, L, Viktor, M.J., Rose, S.H., Viljoen-Bloom, M., van Zyl W.H., Basaglia, M., Cagnin, L., \& Casella, S., 2015. Consolidated bioprocessing of starchy substrates into ethanol by industrial Saccharomyces cerevisiae strains secreting fungal amylases. Biotechnology Bioenginering, 112:1751-60.

Fujita, H., Qian, Q., Fujii, T., Mochizuki, K. \& Sakoda 2011. Isolation of ethanol from its aqueous solution by liquid phase adsorption and gas phase desorption using molecular sieving carbon. Adsorption 17: 869-879.

Genencor STARGEN TM 0022009 are trademarks of Danisco US Inc. in the United States

Hargono, H., Jos, B., \& Kumoro, A.C. 2017 Kinetics of the Enzymatic Hydrolysis of Sweet Cassava Starch and Bitter Cassava Flour and Gadung (Dioscorea hispida Dennst) Flour at Low Temperature. Bull. Chem. React. Eng. Catal. 12(2):256-262.

Hargono, H., Kumoro, A.C., \& Jos, B. 2015 Comparative study on the conventional and non thermal simultaneous saccharification and fermentation of Manihot glaziovii root starch. AIP Conference Proceedings 1699:030013

Huang, H.J., Ramaswamy, S., Tschirner U.W. \& Ramarao, B.V. 2008. A review of separation technologies in current and future biorefineries. Sep Purif Technol. 62(1):1-21.

Jørgensen, H., Kristensen, J.B. \& Felby, C. 2007. Enzymatic conversion of lignocellulose into fermentable sugars: challenges and opportunities. Biofuel Bioprod. Bior. 1:119134.

Karagöz, P., Rocha, I.V., M.Ö. \& Angelidaki, I 2012. Bioresource Technology. 104:349-357
Kusmiyati, Hadiyanto, H. \& Kusumadewi, I. 2016. Bioethanol Production From Iles-Iles (Amorphopallus Campanulatus) Flour by Fermentation Using Zymomonas Mobilis International. Journal of Renewable Energy Development, 9(1):9-14.

Lei, Z., Li, C. \& Chen, B. 2003 Extractive Distillation: A Review. Separation \& Purification Reviews. 32:121-213

Scordia, D., Cosentino, S.L., \& Jeffries, T.W. 2010. Perennial grasses as lignocellulosic feedstock for second-generation bioethanol production in Mediterranean environment. Bioresource Technology. 101(14):5358-65

Scordia, D, Cosentino, S,L, Lee, J.W., \& Jeffries, T.W. 2012 Bioconversion of giant reed (Arundo donax L.) hemicellulose hydrolysate to ethanol by Scheffersomyces stipitis CBS6054. Biomass Bioenergy. 39:296-305.

Shaheen, S.M., Rinklebe, J., Frohne, T., White, J.R., \& Delaune, R.D. 2013 Biogeochemical Factors Governing $\mathrm{Co}, \mathrm{Ni}, \mathrm{Se}$, and $\mathrm{V}$ Dynamics in Periodically Flooded Egyptian North Nile Delta Rice Soils. Soil Science Society of America Journal,78(3):1065-1078.

Silva, C.F.L.E., Schirmer, M.A., Maeda, R.N., Barcelos, C.A., Pereira, N. 2015. Potential of giant reed (arundo donax I.) for second generation ethanol production. Electron. Journal Biotechnology 18:10-15.

Utama, G. L., Kurnani, T.B.A., \& Balia, R.L., 2016. Selection of Mozzarella Cheese Whey Native Yeasts with Ethanol and Glucose Tolerance Ability. International Journal on Advanced Science, Engineering and Information Technology. 6:252-257.

Vane, L.M., Alvarez, F.R., Rosenblum, L., \& Govindaswamy, S. 2013. Efficient Ethanol Recovery from Yeast Fermentation Broth with Integrated Distillation-Membrane Process. Industrial \& Engineering Chemistry Research. 52(3):1033-1041.

Wei, X.Z., Liu, X.F., Zhu, B.K. \& Xu, Y.Y. 2009. Membranes of crosslinked hyperbranch polymers and their pervaporation properties. Desalination, 247(1-3): 647-656. 